\title{
Photoluminescence of oxygen vacancies and hydroxyl group surface functionalized $\mathrm{SnO}_{2}$ nanoparticles
}

\author{
Venkataramana Bonu, ${ }^{* a}$ Arindam Das, ${ }^{* a}$ S. Amirthapandian, ${ }^{\mathrm{b}}$ Sandip Dhara, ${ }^{\mathrm{a}}$ and Ashok Kumar Tyagi ${ }^{\mathrm{a}}$
}

We report, for the first time, the luminescence property of the hydroxyl group surface functionalized quantum dots (QDs) and nanoparticles (NPs) of $\mathrm{SnO}_{2}$ using low energy excitations of $2.54 \mathrm{eV}(488 \mathrm{~nm})$ and $2.42 \mathrm{eV}(514.5 \mathrm{~nm})$. This luminescence is in addition to generally observed luminescence from ' $\mathrm{O}$ ' defects. The as-prepared $\mathrm{SnO}_{2}$ quantum dots (QDs) are annealed at different temperatures in ambient conditions to create varied NPs in size. Subsequently, average size of the NPs is calculated from the acoustic vibrations observed at low frequencies in the Raman spectra and by the transmission electron microscopic measurements. Detailed photoluminescence studies with $3.815 \mathrm{eV}(325 \mathrm{~nm})$ excitation reveal the nature of in-plane and bridging ' $\mathrm{O}$ ' vacancies as well as adsorption and desorption occurred at different annealing temperatures. X-ray photoelectron spectroscopy studies also support this observation. Defect level related to the surface - $\mathrm{OH}$ functional groups shows a broad luminescence peak around 1.96 $\mathrm{eV}$ in $\mathrm{SnO}_{2}$ NPs which is elaborated with the help of temperature dependent studies.

\section{Introduction}

$\mathrm{SnO}_{2}$ is an $n$-type wide band gap (3.6 eV) semiconductor. The wide usage it in the areas such as gas sensing, transparent electrodes, catalyst, solar cell, Li-ion batteries made $\mathrm{SnO}_{2}$ a technologically important material. ${ }^{1}$ In all these important applications defects in $\mathrm{SnO}_{2}$ play a vital role. ${ }^{1-4}$ Prominent defects in $\mathrm{SnO}_{2}$ crystals are ' $\mathrm{O}$ ' vacancies, which create donor states showing $n$-type behavior. ${ }^{1}$ Electrons from these donor states will participate in the formation of a depletion layer on the surfaces of $\mathrm{SnO}_{2}$ crystals which is important for the gas detection process. In our earlier report in-plane ' $\mathrm{O}$ ' $\left(\mathrm{O}^{\mathrm{P}}\right)$ and bridging ' $\mathrm{O}$ ' $\left(\mathrm{O}^{\mathrm{B}}\right)$ vacancy defects were found to play crucial role in the detection of $\mathrm{CH}_{4}$ gas at low temperatures. ${ }^{5}$ Combination of shallow donor levels and wide band gap made this material transparent conductor. ${ }^{6-9}$ Ferromagnetic nature in the $\mathrm{SnO}_{2}$ nanostructures was also ascribed to the ' $\mathrm{O}$ ' defects. ${ }^{10-12}$ The above discussions emphasizes the importance of defects in $\mathrm{SnO}_{2}$ and investigation of their properties. A broad photoluminescence (PL) peak observed for $\mathrm{SnO}_{2}$ nanostructures around $\sim 2 \mathrm{eV}$ was ascribed to oxygen vacancy related defects. ${ }^{12-15}$ After controled annealling of the amorphous $\mathrm{SnO}_{2}$ thin films, sharp ultra violet light was found to emit which was utilized in fabricating diode with $p$-GaN. ${ }^{16}$ Therefore improved understanding to gain the control over the oxygen defects in $\mathrm{SnO}_{2}$ is technologically important.

Along with ' $\mathrm{O}$ ' related defects, formation of hydroxyl (-OH) groups on the surface of $\mathrm{SnO}_{2}$ creates another important point defects. Water can readily dissociate even on ideal oxide surfaces at room temperature. ${ }^{17}$ In the case of nanoparticles (NPs), which possess a large number of surface defects, a high density of under-coordinated metal and oxygen atoms drastically increase chemisorptions of the polar molecule in the ambient conditions. These -OH groups on metal oxides considerably affect the electronic properties and surface chemistry of $\mathrm{SnO}_{2} \cdot{ }^{18-21}$ For instance, formation of - $\mathrm{OH}$ groups on the metal oxides increases density of electrons in the conduction band. ${ }^{18}$ It also influences optical property as shown by Sharma et al. for ZnO NPs. They observed a PL peak around $2.1 \mathrm{eV}$ due to the $-\mathrm{OH}$ functionalization. $^{22}$ Using density functional theory (DFT) calculations, Valentin et al. ${ }^{23}$ showed the electron trapping nature of $-\mathrm{OH}$ group present on the $\mathrm{TiO}_{2}$ surfaces. Similarly, DFT calculations of $-\mathrm{OH}$ groups attached to $\mathrm{Si}$ surfaces revealed formation of donor defect states due to certain kind of Si-OH. ${ }^{24}$ Based on various factors (e.g., season, temperature, location) moisture in atmosphere can vary from ca. 0.1 up to $4 \mathrm{vol} \%$, which notably changes the electronic properties of the sensors and influences their sensitivity. ${ }^{24}$

There are studies on the annealing effect on ' $\mathrm{O}$ ' defects of the crystalline $\mathrm{SnO}_{2}$ and desorption of ' $\mathrm{O}$ ' with temperature. ${ }^{14}$ In this context, there is lack of detailed investigation on the luminescence properties of the oxidation and desorption process of 'O' for quantum dots (QDs) and nanostructures of $\mathrm{SnO}_{2}$. Additionally, there is scope of detailing luminescence study on the role of $-\mathrm{OH}$ groups that are ubiquitously present on the $\mathrm{SnO}_{2}$ NPs surfaces.

Here we present luminescence properties of ' $\mathrm{O}$ ' vacancy defects in the $\mathrm{SnO}_{2}$ QDs and -OH functionalized $\mathrm{SnO}_{2}$ NPs. A systematic study is conducted for the influence of annealing temperature on the size of the NPs. The sizes were calculated from the low frequency Raman scattering (LFRS) and was correlated to high resolution transmission electron microscopy (HRTEM) measurements. The $\mathrm{O}^{\mathrm{P}}$ and $\mathrm{O}^{\mathrm{B}}$ vacancies related luminescence were probed by the excitation energy $3.815 \mathrm{eV}$, whereas distinct defect levels created by $-\mathrm{OH}$ groups were elucidated by the low energy excitations of 2.54 and $2.42 \mathrm{eV}$ preserving the pristine nature of the functionalized groups.

\section{Experimental Section}

\section{Synthesis and Characterization}


Detailed synthesis of $\mathrm{SnO}_{2}$ QDs was described in our earlier study [3]. In brief, $\mathrm{NH}_{4} \mathrm{OH}$ (MERCK) was added drop wise in to stannic chloride $\left(\mathrm{SnCl}_{4}\right.$, Alfa Aesar) under magnetic stirring at 80 ${ }^{\circ} \mathrm{C}$. The resulted white gel was washed with Millipore water, and dried at $100{ }^{\circ} \mathrm{C}$. This product is the as-prepared $\mathrm{SnO}_{2}$ QDs and hereafter will be called as sample A $\left(100{ }^{\circ} \mathrm{C}\right)$. The as-prepared pristine material was further annealed at 200, 250, 300, 500 and $800{ }^{\circ} \mathrm{C}$ for $1 \mathrm{~h}$ at ambient conditions in horizontal quartz tube furnace. The samples annealed at different temperatures will be termed as B $\left(200{ }^{\circ} \mathrm{C}\right), \mathrm{C}\left(250{ }^{\circ} \mathrm{C}\right), \mathrm{D}\left(300{ }^{\circ} \mathrm{C}\right), \mathrm{E}\left(500{ }^{\circ} \mathrm{C}\right)$ and $\mathrm{F}$ $\left(800{ }^{\circ} \mathrm{C}\right)$.

HRTEM images were recorded with the aid of Libra 200 Zeiss electron microscope. X-ray diffraction (XRD) patterns (Bruker) were obtained using $\mathrm{Cu}-\mathrm{Ka}\left(1.5406 \mathrm{~A}^{\circ}\right)$ radiation. Micro-Raman spectroscopy (InVia, Reinshaw) was carried out using $514.5 \mathrm{~nm}$ excitation of an Ar+ laser with $1800 \mathrm{gr} / \mathrm{mm}$ grating, and thermo electric cooled CCD detector in the back scattering mode. The PL spectra (InVia, Reinshaw) were acquired using $514.5 \mathrm{~nm}(2.42$ $\mathrm{eV}), 488 \mathrm{~nm}(2.54 \mathrm{eV})$ (excitation of an Ar+ laser) and $325 \mathrm{~nm}$ (3.815 eV) (He-Cd laser) as the excitation sources. Temperature dependent PL measurements were performed in adiabatic stage (Linkam, UK). Fourier transform infrared spectroscopy (FTIR, Bruker MB-3000) was used to probe infrared active vibrational modes.

\section{Results and Discussion}

\section{Structural studies and morphological features}

XRD patterns of the samples A $\left(100{ }^{\circ} \mathrm{C}\right), \mathrm{D}\left(300{ }^{\circ} \mathrm{C}\right)$ and $\mathrm{F}(800$ ${ }^{\circ} \mathrm{C}$ ) are shown in Fig. 1. All diffraction peaks of sample $\mathrm{F}$ are indexed following the rutile tetragonal crystalline phase of $\mathrm{SnO}_{2}$ (JCPDS \#41-1445). No other phase of $\mathrm{SnO}_{2}$ could be obsered. Sharp diffraction peaks in the sample $\mathrm{F}\left(800{ }^{\circ} \mathrm{C}\right)$ indicates presence of long range order in these $\mathrm{SnO}_{2}$ NPs. The broad peaks are observed for the samples A and D at $2 \theta$ values of $26.5^{\circ}, 33.8^{\circ}$, $51.7^{\circ}$, and $64.7^{\circ}$ which closely match to planes (110), (101), (211) and (112) of rutile tetragonal $\mathrm{SnO}_{2}$, respectively. This broadening of diffraction planes can be ascribed to the presence of short range order that is very small crystallites and also to the non uniform strain. ${ }^{25}$ The mean crystallite size was calculated following Debye-Scherrer equation, $\mathrm{R}=0.89 \lambda / \beta \cos \theta$, where $\mathrm{R}=$ mean crystallite size, $\beta$ = full width at half maximum (FWHM). Average sizes of the NPs found to be of $1.9 \pm 0.2 \mathrm{~nm}, 3.9 \pm 0.2 \mathrm{~nm}$ and $23 \pm 1 \mathrm{~nm}$ for the sample A $\left(100^{\circ} \mathrm{C}\right), \mathrm{D}\left(300^{\circ} \mathrm{C}\right)$ and $\mathrm{F}(800$ $\left.{ }^{\circ} \mathrm{C}\right)$, respectively. However in our earlier report ${ }^{25}$ we have shown presence of non uniform strain in the sample A using Williamson-Hall (W-H) plot. After eliminating the non uniform strain contribution to FWHM value, the average size of the sample A was then found to be $2.3 \pm 0.1 \mathrm{~nm}$.

HRTEM image of D $\left(300{ }^{\circ} \mathrm{C}\right)$ is shown in Fig. 2(a). Crystalline (110) plane with a $d$-spacing of $3.38 \AA$ corresponding to rutile $\mathrm{SnO}_{2}$ (JCPDS \#41-1445) is shown as zoomed inset. Mean diameter is $\sim 4.1 \pm 0.2 \mathrm{~nm}$ from the size distribution plot (Fig. 2(b)). TEM image of sample E $\left(500{ }^{\circ} \mathrm{C}\right)$ is shown in Fig. 3(a). The average particle size grows by annealing to $\sim 9 \pm 0.7 \mathrm{~nm}$ as shown in Fig. 3(b). HRTEM image in Fig. 3(c) confirms crystalline (110) plane with a $d$-spacing value of $3.36 \AA$ (inset).

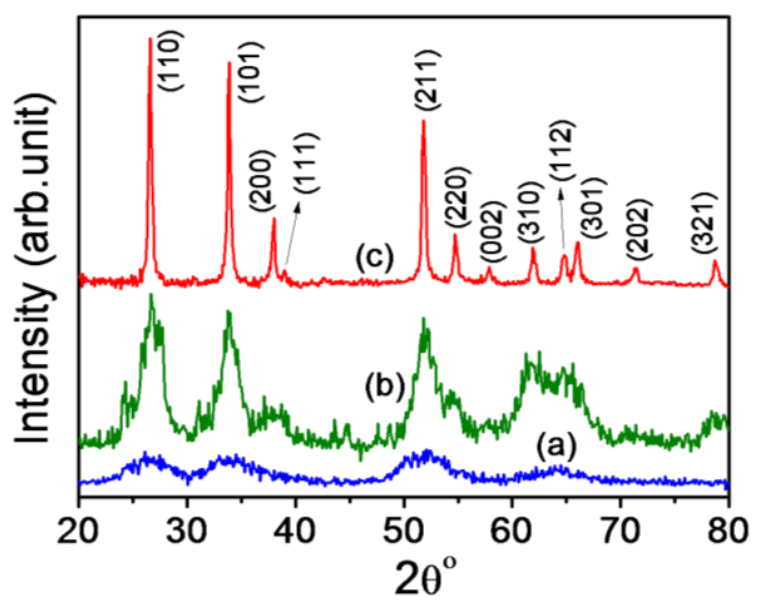

Fig. 1 XRD of samples (a) A $\left(100{ }^{\circ} \mathrm{C}\right)$, (b) D $\left(300{ }^{\circ} \mathrm{C}\right)$ and $(\mathrm{c}) \mathrm{F}$ $\left(800^{\circ} \mathrm{C}\right)$

Fig. 3(d) displays selected area electron diffraction (SAED) pattern. These ring like patterns indicates existance of crystallites in all possible orientations. Rings are indexed as (110), (101) and (211) planes which correspond to the rutile $\mathrm{SnO}_{2}$ phase. Detailed structural characterization of the sample A $\left(100{ }^{\circ} \mathrm{C}\right)$ and $\mathrm{F}(800$ ${ }^{\circ} \mathrm{C}$ ) were discussed in our erlier report. ${ }^{3}$ Average size of the sample A and F were measured using HRTEM and found to be 2.4 and $25 \mathrm{~nm}$, respectively. ${ }^{3}$ Obtained NPs sizes from the TEM match well with XRD results. 

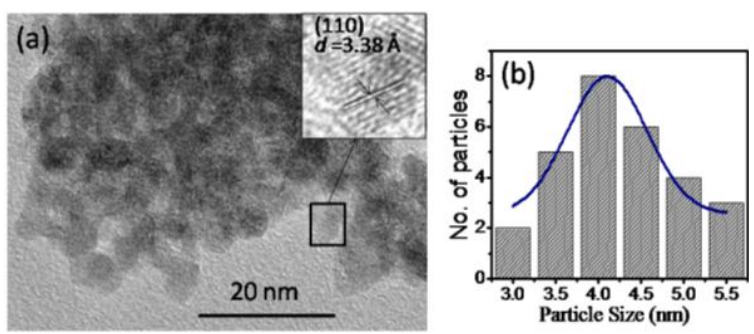

Fig. 2 (a) HRTEM image of $\mathrm{SnO}_{2} \mathrm{NPs}$ annealed at $300{ }^{\circ} \mathrm{C}$. Inset shows crystalline (110) plane of rutile tetragonal $\mathrm{SnO}_{2}$ (b) Gaussian fitting of size distribution curve.
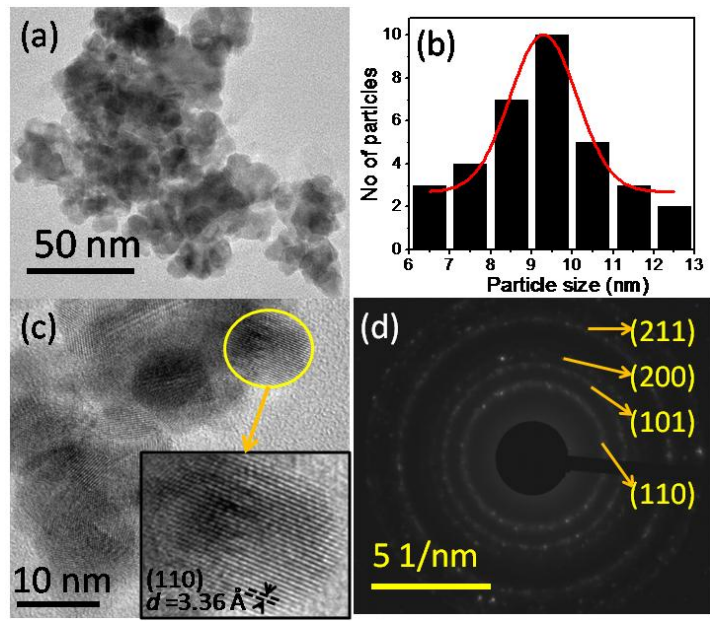

FIG. 3. (a) Low magnification TEM image of sample F (500 oC), (b) Particle size distribution (c) HRTEM image (d) SAED pattern of sample $\mathrm{F}(500 \mathrm{oC})$.

Raman spectra recorded for all the samples are shown in Fig. 4. Raman modes at 474,633 and $775 \mathrm{~cm}^{-1}$ of the annealed samples are assigned to $E_{\mathrm{g}}, A_{1 \mathrm{~g}}$ and $B_{2 \mathrm{~g}}$ symmetries, respectively. ${ }^{26}$ Peak at $575 \mathrm{~cm}^{-1}$ (termed as $D$ ), uniquely found in ultra small $\mathrm{SnO}_{2} \mathrm{NPs}$, is attributed to optically inactive $A_{2 \mathrm{~g}}$ mode by following Matossi force constant model which considers the modified bond length, space symmetry reduction and lattice distortion due to 'O' vacancies in $\mathrm{SnO}_{2} \mathrm{NPs}^{27}$

Low frequency Raman scattering (LFRS) from spherical acoustic vibrations of free $\mathrm{SnO}_{2}$ NPs can be utilized for measuring the mean particle size of NPs. ${ }^{28,29}$ Peak positions of low frequency mode for different particles sizes are shown in Fig. 4. There is observable red shift while the size of the particle increases with annealing temperatures. According to Lamb's theory, size of the NP relates to low frequency $w_{l, n}^{s p h}$ as

$$
w_{l, n}^{s p h}=S_{l, n} \frac{v_{l}}{c R}
$$

Where $v_{l}$ denoting the average transverse sound velocity of $\mathrm{SnO}_{2}$ is $6530 \mathrm{~m} / \mathrm{s},{ }^{28} R$ is the diameter of a NP, and $c$ is velocity of light in vacuum. Coefficient $S_{l, n}=0.887$ strongly depends on the ratio of the transverse to longitudinal, $\mathrm{v}_{\mathrm{t}} / \mathrm{v}_{1}$ sound velocities. ${ }^{29}$ Average particle sizes $2.41 \pm 0.15 \mathrm{~nm}, 2.66 \pm 0.18 \mathrm{~nm}$ and $3.1 \pm$ $0.22 \mathrm{~nm}$ were calculated using LFRS model for the samples A $\left(100{ }^{\circ} \mathrm{C}\right), \mathrm{B}\left(200{ }^{\circ} \mathrm{C}\right)$, and $\mathrm{C}\left(250{ }^{\circ} \mathrm{C}\right)$, respectively. The values are plotted in Fig. 5. Sizes calculated using TEM for samples D (300 $\left.{ }^{\circ} \mathrm{C}\right), \mathrm{E}\left(500{ }^{\circ} \mathrm{C}\right)$ and $\mathrm{F}\left(800{ }^{\circ} \mathrm{C}\right)$ are also indicated in Fig. 5. The sizes of NPs measured by different methodologies are tabulated in the supplementary information (TABLE SI). Due to the limitation of the edge filter in our Raman instrument, modes below $50 \mathrm{~cm}^{-1}$ could not be probed accurately to calculate the average size of other samples.

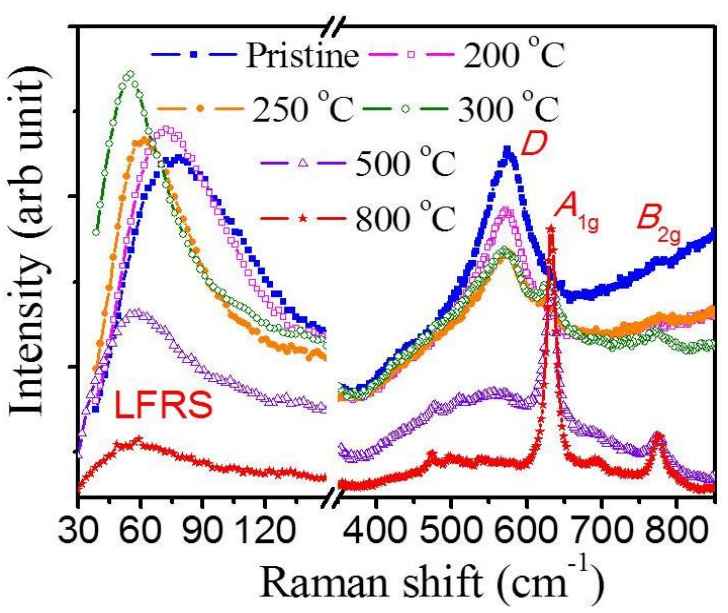

Fig. 4 Raman spectra of $\mathrm{SnO}_{2} \mathrm{NPs}$ annealed at different

As the particle radius goes below the Bohr radius, $r_{\mathrm{B}},(2.7 \mathrm{~nm}$ for $\mathrm{SnO}_{2}{ }^{30}$ ) the electron hole motion is not correlated. In that case, the effective band gap energy is given by,

$$
E_{\mathrm{g}}^{\mathrm{eff}}=E_{\mathrm{g}}+\frac{\hbar^{2} \pi^{2}}{2 \mu r^{2}}-\frac{1.8 \mathrm{e}^{2}}{\varepsilon r}+\cdots
$$

If the NP size is higher than $r_{\mathrm{B}}$, 3rd term (Coulomb interaction) in above equation is considered to be negligible. In the equation, $r$ is the particle radius, and $\mu$ is the effective reduced mass $\left(0.27 \mathrm{~m}_{\mathrm{e}}\right.$ for $\left.\mathrm{SnO}_{2}\right){ }^{31} E_{\mathrm{g}}$ is the bulk band gap energy $(3.6 \mathrm{eV})$ and the dielectric constant of $\mathrm{SnO}_{2}$ is 14. Band gaps of the samples are calculated (supplementary TABLE S1) and plotted with varying NP sizes (Fig. 5). As size of the NPs increases, the corresponding band gap decreases. Size of the NPs does not change considerably until an annealing temperature of $300{ }^{\circ} \mathrm{C}$ with a size of $4.1 \mathrm{~nm}$. Interestingly, NP size drastically increases to $9.5 \mathrm{~nm}$ upon annealing at a temperature of $500{ }^{\circ} \mathrm{C}$. Thus it was inferred that the grain growth, which was the third stage of annealing process started effectively at $500{ }^{\circ} \mathrm{C}$ onwards, whereas other two initial steps of annealing process, recovery and re-crystallization could only take place predominantly until a temperature of 300 ${ }^{\circ} \mathrm{C}$.

XPS analysis for NPs of sizes of 4 , and $25 \mathrm{~nm}$ was carried out and reported earlier. ${ }^{5}$ Atomic weight percentage ratios between 'O' and 'Sn' (O:Sn) were approximately 1.7 and 1.5 for 4 and 25 
$\mathrm{nm}$ NPs, respectively. It indicates increasing oxygen deficiency on the surface of $25 \mathrm{~nm}$ NPs than that of in the $4 \mathrm{~nm}$ NPs. This enhanced defects density manifests as a result of strong

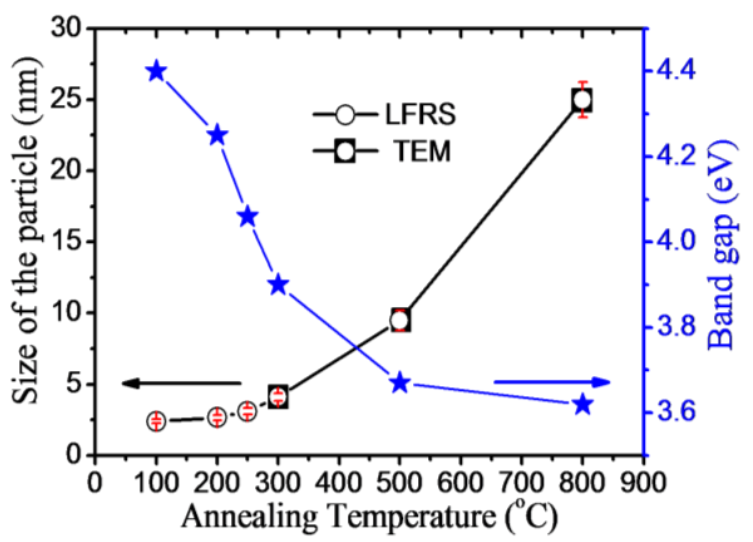

Fig. 5 Size and band gap of the $\mathrm{SnO}_{2}$ NPs with respect to annealing temperature. Symbols $\bigcirc$ and $\square$ represents the sizes determined by using LFRS and TEM studies, respectively. Error bar added for the NPs size values.

desorption of 'O's from the surface of NPs due to annealing of the as-prepared material at high temperatures of $800{ }^{\circ} \mathrm{C}$.

\section{Photoluminescence of ' $O$ ' vacancy related defects.}

PL studies are carried out using excitation energy of $3.815 \mathrm{eV}$ in the ambient conditions. The excitation energy is found to be lower than the band gap of the samples $\mathrm{A}\left(100^{\circ} \mathrm{C}\right), \mathrm{B}\left(200^{\circ} \mathrm{C}\right), \mathrm{C}$ $\left(250{ }^{\circ} \mathrm{C}\right)$ and $\mathrm{D}\left(300^{\circ} \mathrm{C}\right)$ (Fig. 5), and hence defect states only are probed. Fig. 6 shows PL spectra of NPs, which are excited with $3.815 \mathrm{eV}$. A large PL intensity around $2 \mathrm{eV}$ is observed for asprepared QDs $\left(\mathrm{A}\left(100{ }^{\circ} \mathrm{C}\right)\right)$. Similar luminescence pattern is observed for $\mathrm{SnO}_{2}$ nanostructures and it is attributed to ' $\mathrm{O}$ ' defects. ${ }^{5,13,14,32-36}$ Notably, PL intensity around $2 \mathrm{eV}$ (Fig. 6) decreases with the increasing annealing temperature and almost reduces to negligible value for the sample $\mathrm{D}\left(300{ }^{\circ} \mathrm{C}\right)$ of particle size $4.1 \mathrm{~nm}$. It indicates that the defect centres responsible for strong luminescence are annihilated, possibly by oxidation during annealing in air atmosphere. However, PL intensity around $2 \mathrm{eV}$ further increases for the samples $E$ of particle size of $9 \mathrm{~nm}$ and the sample $\mathrm{F}$ of particle size of $25 \mathrm{~nm}$. Here desorption of ' $\mathrm{O}$ ' at high temperature incurs the ' $\mathrm{O}$ ' defects which leads to further enhancement in PL intensity. This observation supports the XPS results. To get a better insight of the various defects, each plot is deconvoluted in to five Gaussian peaks being centred on around
1.8, 1.97, 2.12, 2.29 and $2.45 \mathrm{eV}$. PL spectra with Gaussian peak fittings are shown in the supplementary information Fig. S1(a-e). Peak positions and fractional areas of each peak are given in TABLE I. The fractional area is simply proportional to the fractional number of electronic transitions in these five channels. There are two types of ' $\mathrm{O}$ ' vacancies in the $\mathrm{SnO}_{2}$ crystal which are $\mathrm{O}^{\mathrm{B}}$ and $\mathrm{O}^{\mathrm{P}}$ vacancies (Fig. 7). Yellow luminescence (YL) $(\sim 2$ $\mathrm{eV})$ is attributed to the defect states created by $\mathrm{O}^{\mathrm{B}}$ vacancies $5,13,14$ and the blue-green luminescence (BGL) is due to $\mathrm{O}^{\mathrm{P}}$ vacancies. ${ }^{5,14}$ In Fig. S1, luminescence in the first three channels at $1.8,1.97$ and $2.12 \mathrm{eV}$ are considered to be related to $\mathrm{O}^{\mathrm{B}}$ vacancies whereas luminescence centred at 2.29 and $2.45 \mathrm{eV}$ channels are regarded as a result of $\mathrm{O}^{\mathrm{P}}$ vacancies. Detailed of the luminescence intensity from each of these two types are given in TABLE I. For sample A of particle size $2.4 \mathrm{~nm}$, fraction of YL and BGL are $73.3 \%$ and $26.7 \%$, respectively. After annealing the sample at 200 and $250{ }^{\circ} \mathrm{C}$, YL fractions increase to $77 \%$ and $80 \%$ along with improvement in particle sizes to $2.66 \mathrm{~nm}$ and 3.1 $\mathrm{nm}$, respectively. Mean while contribution of the BGL reduces to $23 \%$ and $20 \%$ for 2.66 and $3.1 \mathrm{~nm} \mathrm{NPs,} \mathrm{respectively.} \mathrm{This}$ variation infers that $\mathrm{O}^{\mathrm{P}}$ vacancy defects are annihilated faster than the $\mathrm{O}^{\mathrm{B}}$ defects at these temperatures (TABLE I, Fig. S1).

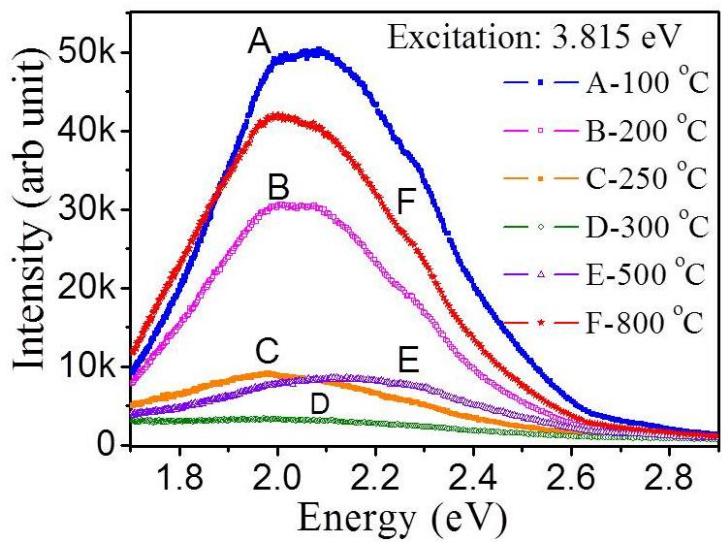

Fig. $6 \mathrm{PL}$ of $\mathrm{SnO}_{2} \mathrm{NPs}$ annealed at different temperatures with excitation energy $3.815 \mathrm{eV}(325 \mathrm{~nm})$.

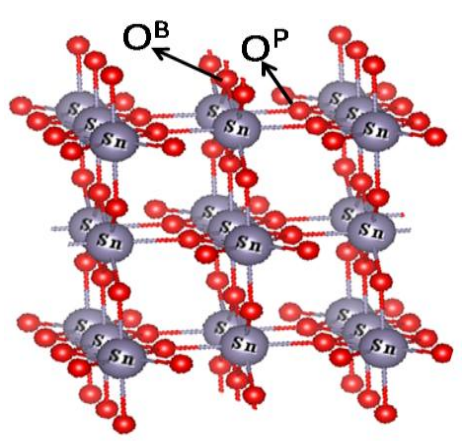

Fig. 7 Rutile tetragonal structure of $\mathrm{SnO}_{2} . \mathrm{O}^{\mathrm{P}}$ : in-plane

oxygen, $\mathrm{O}^{\mathrm{B}}$ : Bridging oxygen. 
TABLE I. Gaussian deconvolution parameters of the spectra shown in Fig. 2.

\begin{tabular}{|c|c|c|c|c|c|c|c|c|}
\hline \multirow{3}{*}{$\begin{array}{c}\mathrm{A} \\
\left(100^{\circ} \mathrm{C}\right)\end{array}$} & Position & 1.83 & 1.99 & 2.14 & Total YL & 2.29 & 2.45 & $\begin{array}{l}\text { Total } \\
\text { BGL }\end{array}$ \\
\hline & Area & 2,788 & 9,720 & 8,243 & 20,751 & 5,959 & 1,544 & 7503 \\
\hline & $\%$ & $9.8 \%$ & $34.4 \%$ & $29.1 \%$ & $73.3 \%$ & $21.3 \%$ & $5.4 \%$ & $26.7 \%$ \\
\hline \multirow{3}{*}{$\begin{array}{c}\mathrm{B} \\
\left(200^{\circ} \mathrm{C}\right)\end{array}$} & Position & 1.81 & 1.97 & 2.12 & & 2.29 & 2.47 & \\
\hline & Area & 2,607 & 4,524 & 4,777 & 11,908 & 2,581 & 959 & 3,540 \\
\hline & $\%$ & $16.8 \%$ & $29.2 \%$ & $30.9 \%$ & $77 \%$ & $16.7 \%$ & $6.2 \%$ & $23 \%$ \\
\hline \multirow{3}{*}{$\begin{array}{c}\mathrm{C} \\
\left(250^{\circ} \mathrm{C}\right)\end{array}$} & Position & 1.77 & 1.96 & 2.13 & & 2.29 & 2.46 & \\
\hline & Area & 1,015 & 1,550 & 1,060 & 3,625 & 556 & 314 & 870 \\
\hline & $\%$ & $22 \%$ & $34.5 \%$ & $23.6 \%$ & $80 \%$ & $12.3 \%$ & $7 \%$ & $20 \%$ \\
\hline \multirow{3}{*}{$\begin{array}{c}E \\
\left(500^{\circ} \mathrm{C}\right)\end{array}$} & Position & 1.77 & 1.97 & 2.13 & & 2.29 & 2.46 & \\
\hline & Area & 457 & 979 & 1,167 & 2,603 & 896 & 387 & 1,283 \\
\hline & $\%$ & $12 \%$ & $25.2 \%$ & $30 \%$ & $67 \%$ & $23 \%$ & $10 \%$ & $33 \%$ \\
\hline \multirow{3}{*}{$\begin{array}{c}\mathrm{F} \\
\left(800^{\circ} \mathrm{C}\right)\end{array}$} & Position & 1.81 & 1.96 & 2.11 & & 2.26 & 2.45 & \\
\hline & Area & 3,228 & 5,418 & 5,485 & 14,131 & 4,407 & 1,251 & 5,658 \\
\hline & $\%$ & $16.3 \%$ & $27.3 \%$ & $27.7 \%$ & $71 \%$ & $22.2 \%$ & $6.3 \%$ & $29 \%$ \\
\hline
\end{tabular}

Sample D $\left(300{ }^{\circ} \mathrm{C}\right)$ does not show any significant PL intensity around $2 \mathrm{eV}$ (Fig. 6). In sample $\mathrm{E}\left(500{ }^{\circ} \mathrm{C}\right)$ of particle size $9 \mathrm{~nm}$ YL fraction decreases to $67 \%$ while BGL increases to $33 \%$ (TABLE I). With respect to sample $\mathrm{A}, \mathrm{O}^{\mathrm{P}}$ vacancy fraction is found to be higher than that of the $\mathrm{O}^{\mathrm{B}}$ defects for the sample $\mathrm{E}$. The YL and BGL fractions change to $71 \%$ and $29 \%$ for sample $\mathrm{F}\left(800{ }^{\circ} \mathrm{C}\right)$ of particle size $25 \mathrm{~nm}$ (TABLE I). It is understandable from the above analysis that a dominant oxidation process takes place at low temperature of $200{ }^{\circ} \mathrm{C}$ unlike the oxidation at high temperature for thin film sample. ${ }^{37}$ Rate of annihilation process of $\mathrm{O}^{\mathrm{P}}$ is found to be high in comparison to the $\mathrm{O}^{\mathrm{B}}$ vacancies (TABLE I). At high annealing temperature of $800{ }^{\circ} \mathrm{C}$, the $\mathrm{O}^{\mathrm{B}}$ vacancies are found to dominate over $\mathrm{O}^{\mathrm{P}}$ vacancies. It is understandable that significant grain growth started at $500{ }^{\circ} \mathrm{C}$ as discussed in the previous section. At this temperature small grains will come together to form a big particle in order to reduce free energy of the system. In this process of growth from $2.4 \mathrm{~nm}$ to $9.5 \mathrm{~nm}, \mathrm{O}^{\mathrm{P}}$ vacancies are created as effectively as $\mathrm{O}^{\mathrm{B}}$ vacancies. At annealing temperature of $800{ }^{\circ} \mathrm{C}$, total PL intensity increases strongly indicating occurrence of large defects on the surface of NPs. In this sample $\mathrm{O}^{\mathrm{P}}$ vacancy percentage is much less than that of the $\mathrm{O}^{\mathrm{B}}$ vacancy percentage. It is noteworthy that the vacancy creation energy is higher for $\mathrm{O}^{\mathrm{P}}$ than that of $\mathrm{O}^{\mathrm{B}} \cdot{ }^{38}$ In summary, ' $\mathrm{O}$ ' vacancies $\left(\mathrm{O}^{\mathrm{B}}\right.$ and $\left.\mathrm{O}^{\mathrm{P}}\right)$ are very high in the sample $\mathrm{A}$ of size $2.4 \mathrm{~nm}$. However, major contribution to PL intensity is from (73.3\%) from $\mathrm{O}^{\mathrm{B}}$ vacancies. After annealing the sample $\mathrm{A}$ at 200 and $250{ }^{\circ} \mathrm{C}$ the NPs sizes increase to 2.66 and $3.1 \mathrm{~nm}$, respectively and the overall ' $\mathrm{O}$ ' vacancies are found to decrease. At this low temperature annealing process $\mathrm{O}^{\mathrm{B}}$ vacancy percentage increases over $\mathrm{O}^{\mathrm{P}}$ vacancy percentage (TABLE 1). Oxygen defects are considerably low for the NPs of size of $4 \mathrm{~nm}$, which is obtained by annealing the sample A at $300{ }^{\circ} \mathrm{C}$. Similarly annealed sample at $500{ }^{\circ} \mathrm{C}(9 \mathrm{~nm})$, the PL intensity starts increasing. Here
$\mathrm{O}^{\mathrm{P}}$ vacancy percentage also increases. Interestingly it has the highest percentage among all the samples (TABLE 1). Both ' $O$ ' vacancies $\left(\mathrm{O}^{\mathrm{B}}\right.$ and $\left.\mathrm{O}^{\mathrm{P}}\right)$ increases further for the $25 \mathrm{~nm}$ NPs over the $9 \mathrm{~nm} \mathrm{SnO}_{2}$ NPs. However, $\mathrm{O}^{\mathrm{P}}$ vacancy percentage is found to decrease.

\section{Photoluminescence of $-\mathrm{OH}$ group related defects}

PL studies of $\mathrm{SnO}_{2}$ NPs are also conducted using low energy excitations of $2.42 \mathrm{eV}$ and $2.54 \mathrm{eV}$. Fig. 8 shows the PL spectra with the excitation energy of $2.42 \mathrm{eV}$. At a glance, the peak around $1.96 \mathrm{eV}$ appears due to luminescence from the NPs. However after testing with another excitation of $2.54 \mathrm{eV}$ (Fig. 9), it turns out to be a Raman mode related to $-\mathrm{OH}$ vibration $(\sim 3400$ $\left.\mathrm{cm}^{-1}\right)$. The observed Raman shift is consistent with respect to both the excitations and matches to the reported data for hydroxyl group as typical $\mathrm{Sn}-\mathrm{OH}$ vibration mode. ${ }^{39,40}$ In support to the presence of $-\mathrm{OH}$ group, FTIR measurements are also conducted typically on the samples $\mathrm{C}\left(250{ }^{\circ} \mathrm{C}\right)$ and $\mathrm{F}\left(800{ }^{\circ} \mathrm{C}\right)$. It confirms the strong presence of $-\mathrm{OH}$ groups in the sample $\mathrm{C}$ (Fig. 10). Peaks at 587, 1640 and $3400 \mathrm{~cm}^{-1}$ are ascribed to various $\mathrm{Sn}-\mathrm{OH}$ vibrations. ${ }^{39}$ Strong presence of these peaks in the sample C (250 $\left.{ }^{\circ} \mathrm{C}\right)$ over the sample $\mathrm{F}\left(800{ }^{\circ} \mathrm{C}\right)$ indicates the presence of high amount of $-\mathrm{OH}$ groups in low annealing temperature samples. Peak at $624 \mathrm{~cm}^{-1}$ is assigned to the bulk O-Sn-O vibrational mode and is found to be strong in the sample $\mathrm{F}\left(800^{\circ} \mathrm{C}\right)$ relative to the sample $\mathrm{C}\left(250^{\circ} \mathrm{C}\right)$. Defect related peaks at $2.34 \mathrm{eV}$ corresponding to Raman mode at $575 \mathrm{~cm}^{-1}(D$ mode $)$ and $2.33 \mathrm{eV}\left(A_{1 \mathrm{~g}}\right.$ mode at $\left.632 \mathrm{~cm}^{-1}\right)$ are also seen in Fig. 8. These Raman modes are discussed (Fig. 4) previously. Apart from these Raman modes there is an interesting luminescence background around $1.96 \mathrm{eV}$. The same luminescence is observed with an excitation of $2.54 \mathrm{eV}$ also (Fig. 9). In contrast to the PL intensity observed in Fig. 6, intensities in Figs. 8 and 9 are increased with annealing 
temperature and then it decreases for high annealing temperatures. Highest luminescence intensity is observed for the sample D $\left(300{ }^{\circ} \mathrm{C}\right)$ with a $2.42 \mathrm{eV}$ excitation energy (Fig. 8).

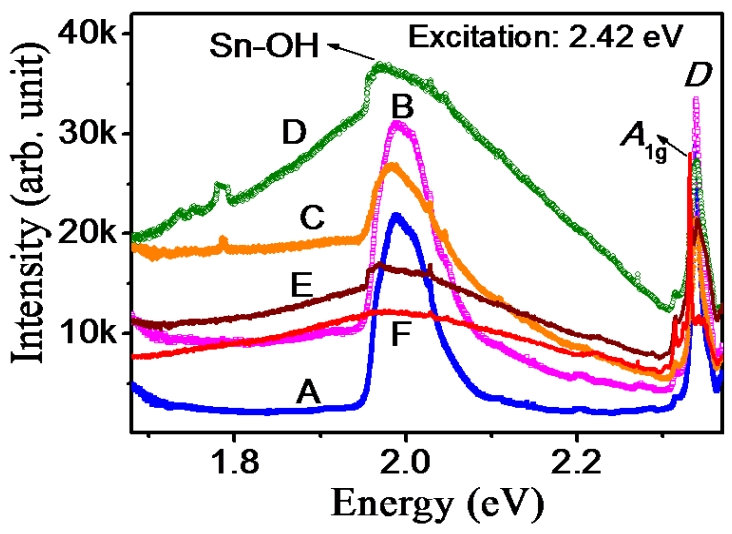

Fig. 8. Photoluminescence of $\mathrm{SnO}_{2} \mathrm{NPs}$ annealed at different temperatures with excitation energy $2.42 \mathrm{eV}(514.5 \mathrm{~nm})$.

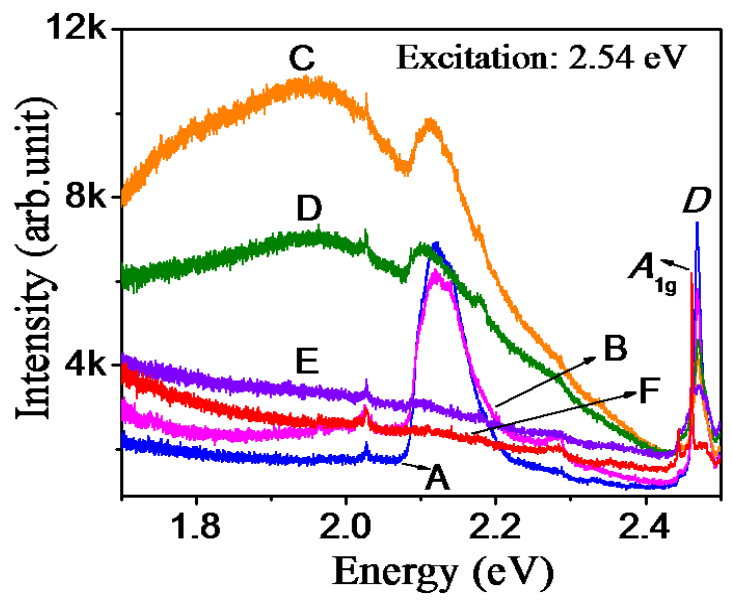

Fig. 9 Photoluminescence of $\mathrm{SnO} 2 \mathrm{NPs}$ annealed at different temperatures with excitation energy $2.54 \mathrm{eV}(488 \mathrm{~nm})$.

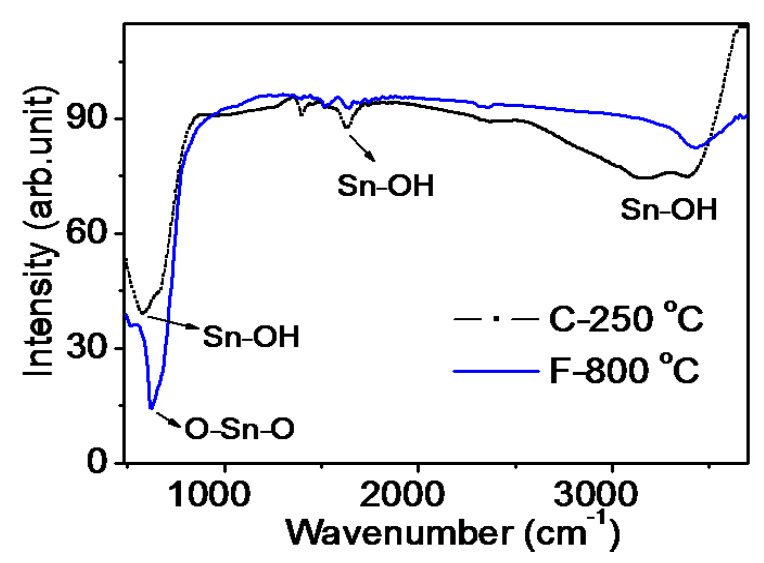

Fig.10 FTIR of $\mathrm{SnO}_{2}$ NPs.
Whereas $2.54 \mathrm{eV}$ excitation offers highest luminescence intensity (Fig. 9) for the sample $\mathrm{C}\left(250{ }^{\circ} \mathrm{C}\right)$ among all NPs. Samples A $\left(100{ }^{\circ} \mathrm{C}\right)$ and $\mathrm{B}\left(200{ }^{\circ} \mathrm{C}\right)$ have nearly no luminescence intensity while the sample $\mathrm{F}\left(800{ }^{\circ} \mathrm{C}\right)$ has considerably low PL intensity with the $2.42 \mathrm{eV}$ excitation (Fig. 8). All these three samples emit large luminescence intensity with the excitation of $3.815 \mathrm{eV}$ (Fig. 6). Sample D $\left(300{ }^{\circ} \mathrm{C}\right)$ shows hardly any luminescence with the $3.815 \mathrm{eV}$ excitation (Fig. 6), whereas high PL intensity results for the same sample with low energy excitations of $2.54 \mathrm{eV}$ and 2.42 $\mathrm{eV}$ (Figs. 8 and 9). From the above observations, the origin of the luminescence with low excitation energies (Figs. 8 and 9) strongly differs from the origin of luminescence with the high excitation energy (Fig. 6). Hence the luminescence observed in the low energy excitation may not be related to the ' $O$ ' vacancies. It was reported that the $-\mathrm{OH}$ groups on oxides were acted as luminescence centres. Luminescence around $2.1 \mathrm{eV}$ was observed in $\mathrm{ZnO}$ NPs due to the presence of $-\mathrm{OH}$ groups. ${ }^{22} \mathrm{R}$. G. Pavelko et al. showed using time-resolved diffuse reflectance in situ FTIR spectroscopy (DRIFTS) and mass spectrometry (MS) analysis that the -OH groups formation at bridging ' $\mathrm{O}$ ' site of $\mathrm{SnO}_{2}$ induced huge number of ' $O$ ' vacancies which acted as major donor states. Moreover, these bridging hydroxyl groups and surface oxygen closely interacted and participated in the creation of surface donor states. These donor states reduced the resistance of the material. ${ }^{41}$ Based on these observations we may attribute the observed luminescence with low energy excitation to - $\mathrm{OH}$ groups formed on the $\mathrm{SnO}_{2}$ NPs.

Samples A $\left(100{ }^{\circ} \mathrm{C}\right)$ and $\mathrm{B}\left(200{ }^{\circ} \mathrm{C}\right)$ (Fig. 8) have high intensity of $\mathrm{Sn}-\mathrm{OH}$ Raman vibrational mode. However, these two samples do not show any luminescence for low energy excitations (Figs. 8 and 9). From the literature it is clear that the conduction of oxides increases after formation of $-\mathrm{OH}$ groups on surface and it forms donor states close to the conduction band. ${ }^{18,23,24,41}$ Optical band gap of the samples A and B are found to be around 4.45 and $4.25 \mathrm{eV}$, respectively (Fig. 5). Donor states created by $-\mathrm{OH}$ groups in these two samples are close to the conduction band and the excitation energies $2.54 \mathrm{eV}$ and $2.42 \mathrm{eV}$ are not sufficient to excite the electrons from valence band to $\mathrm{OH}$ group related defect energy state. However, highest luminescence intensities are shown by the sample $\mathrm{C}\left(250{ }^{\circ} \mathrm{C}\right)$ and $\mathrm{D}\left(300{ }^{\circ} \mathrm{C}\right)$, having low band gaps around 4.06 and $3.90 \mathrm{eV}$, with the low energy excitations of 2.54 and $2.42 \mathrm{eV}$ respectively. Noteworthy, luminescence related to $-\mathrm{OH}$ is not observed for the same sample D $\left(300{ }^{\circ} \mathrm{C}\right)$ with the excitation energy of $3.815 \mathrm{eV}$ (Fig. 6). This is ascribed to the heat energy due to the absorption of $3.815 \mathrm{eV}$ which in turn destroys the $-\mathrm{OH}$ groups. Importantly, we do not observe any - $\mathrm{OH}$ related Raman peak with $325 \mathrm{~nm}$ (3.815 eV) laser for the samples C, D, E and F (supplementary Fig. S2). This observation supports instability of $-\mathrm{OH}$ functional group with the high excitation energy.

To get a better understanding on luminescence of $-\mathrm{OH}$ defect states, we have performed temperature dependent PL study. Sample B $\left(200{ }^{\circ} \mathrm{C}\right)$ is chosen for this study with an excitation energy of $2.42 \mathrm{eV}$. There is hardly any luminescence at room temperature (Fig. 11), as $2.42 \mathrm{eV}$ is not sufficient for exciting the $-\mathrm{OH}$ defect states in sample $\mathrm{B}$, as discussed earlier. Interestingly luminescence is not observed at temperatures of 50, 100 and 150 ${ }^{\circ} \mathrm{C}$ also. Luminescence appears at the temperature of $200{ }^{\circ} \mathrm{C}$. It is 


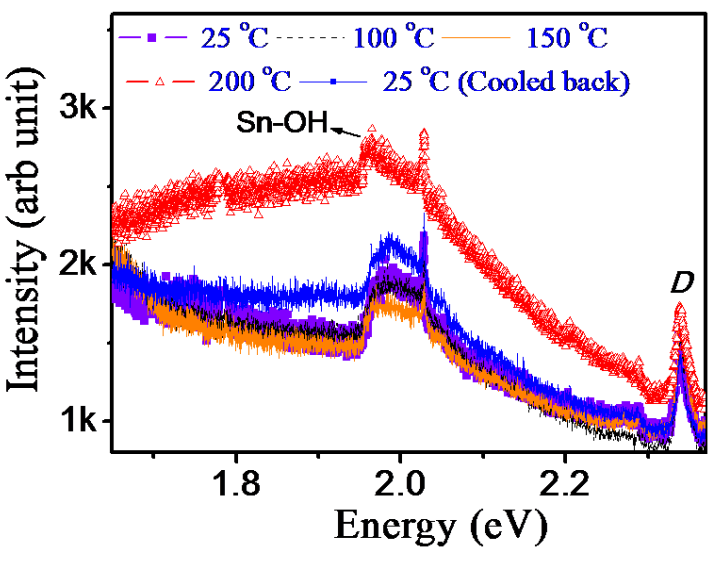

Fig. 11 Temperature dependent PL study of sample B $\left(200{ }^{\circ} \mathrm{C}\right)$

with excitation energy of $2.42 \mathrm{eV}$.

noteworthy that the band gap of a semiconductor decreases as the temperature increases. ${ }^{42}$ In the present study, until a temperature of $200{ }^{\circ} \mathrm{C}$, sufficient energy to the electrons is not provided. In consequence, electrons could not reach to the corresponding defect energy state. After recording PL at $200{ }^{\circ} \mathrm{C}$, the material is cooled down to $25{ }^{\circ} \mathrm{C}$ and subsequent $\mathrm{PL}$ spectrum is now recorded. The corresponding PL intensity decreases and it almost matches to the room temperature PL intensity. The corresponding Raman peak shape for - $\mathrm{OH}$ group appears again as seen before exposing to the heating. It explains that $-\mathrm{OH}$ related defect band with $2.42 \mathrm{eV}$ can be reached only after providing a minimum temperature of $200{ }^{\circ} \mathrm{C}$. The energy supplied by $200{ }^{\circ} \mathrm{C}$ may be low, however, the subsequent reduction in band gap $^{42}$ and possible two step excitation process ${ }^{43}$ might have helped in exciting the electron to the $-\mathrm{OH}$ group related defect state. This experiment offers further support for the defect band as presumed in samples $\mathrm{A}\left(100{ }^{\circ} \mathrm{C}\right)$ and $\mathrm{B}\left(200{ }^{\circ} \mathrm{C}\right)$ which cannot be attained using low energy excitations of 2.54 and $2.42 \mathrm{eV}$. Sn-OH vibrational mode recovers well after cooling down to room temperature by absorbing moisture from experimental ambient conditions (Fig. 11). This feature can be utilized in understanding the presence of the moist environment.

\section{Conclusion}

Photoluminescence intensities of $\mathrm{SnO}_{2}$ QDs around $2 \mathrm{eV}$ was correlated to various ' $\mathrm{O}$ ' related defects which was found to decrease with increasing annealing temperature up to $300{ }^{\circ} \mathrm{C}$. Further increase in the luminescence intensity with increasing annealing temperature was detected for the large NPs and was accounted for defects arising due to desorption of oxygen occurred on the surface of NPs at high temperatures. In addition to oxygen vacancy related defects, luminescence with low energy excitations from the $-\mathrm{OH}$ group defects is first time elucidated for the $\mathrm{SnO}_{2}$ NPs. It is well known that the defects in $\mathrm{SnO}_{2}$ play a crucial role in its powerful applications. We believe that the information provided here related to ' $\mathrm{O}$ ' vacancies and $-\mathrm{OH}$ group functionalization of $\mathrm{SnO}_{2}$ will help greatly to understand the nature of defects, so that one can manipulate them for efficient use of $\mathrm{SnO}_{2}$ in technologically important applications.

\section{Acknowledgement}

We thank Dr. Manas Sardar, MPD, MSG, IGCAR for the valuable discussions.

\section{Notes and references}

${ }^{a}$ Surface and Nanoscience Division, ${ }^{b}$ Materials Physics Division, Indira Gandhi Center for Atomic Research, Kalpakkam-603102, India. E-mail: dasa@igcar.gov.in,ramana9hcu@gmail.com

$\dagger$ Electronic Supplementary Information (ESI) available: [Table .S1, Gaussian fitting of PL spectra in Fig. 6 (Fig.S1) and Raman spectra of NPs with $325 \mathrm{~nm}$ (Fig. S2)]. See

DOI: $10.1039 / \mathrm{b} 000000 \mathrm{x} /$

\section{References}

1) M. Batzill and U. Diebold, Progress in Surface Science, 2005, 79, 47.

2) P. G. Harrison and M. J. Willett, Nature, 1988, 332, 24.

3) V. Bonu, A. Das, S. Dhara, S. Amirthapandian, and A. K. Tyagi, Sci. Adv. Mater., 2013, 7, 865.

4) J. Lin, Z. Peng, C. Xiang, G. Ruan, Z. Yan, D. Natelson and J. M. Tour, ACS Nano, 2013, 7, 6001.

5) Bonu. VenkataRamana, A. Das, A. K. Prasad, N. Gopala Krishna, S. Dhara, A. K. Tyagi, Appl. Phys. Lett. 2014, 105, 243102.

6) Ç. Kılıç and A. Zunger, Phy. Rev. Lett., 2002, 88, 4.

7) Y. S. He, J. C. Campbell, R. C. Murphey, N. F. Arendt and J. S. Swinnea, J. Mater. Res., 1993, 8, 3131.

8) S. Samson and C. G. Fonstad, J. Appl. Phys., 1973, 44, 4618.

9) C. G. Fonstad and K. H. Rediker, J. Appl. Phys., 1971, 42, 2911.

10) G. S. Chang, J. Forrest, E. Z. Kurmaev, A. N. Morozovska, M. D. Glinchuk, J. A. McLeod, A. Moewes, T. P. Surkova and H. H. Nguyen, Phy. Rev. B., 2012, 85, 165319.

11) A. Sundaresan, R. Bhargavi, N. Rangarajan, U. Siddesh and C. N. Rao, Phy. Rev. B, 2006, 74, 161306R.

12) V. Bonu, A. Das, M. Sardar, Sandip Dhara, A. K. Tyagi, J. Mater. Chem. C, 2015, DOI: 10.1039/C4TC02210FL.

13) S. Lettieri, M. Causà, A. Setaro, F. Trani, V. Barone, D. Ninno, and

P. Maddalena, J. Chem. Phy., 2008, 129, 244710.

14) D. Prades, J. Arbiol, A. Cirera, J. R. Morante, M. Avella, L. Zanotti,

E. Comini, G. Faglia and G. Sberveglieri, Sensors and Actuators B,

2007, 126, 6 . 

Appl. Phy. Lett. 2005, 86, 011923.

L. Yongfeng, Y. Wanjian, D. Rui, C. Rui, C. Jing, Y. Qingyu, Y. Bin, S. Handong, W. Su-Huai, and W. Tom, NPG Asia Mater., 2012, 4, 1.

17) M. A. Henderson, Surf. Sci. Rep., 2002, 46, 1-308.

F. Hernandez-Ramirez1, S. Barth2,3, A. Tarancon1, O. Casals1, E. Pellicer1, J. Rodriguez1, A. Romano-Rodriguez1, J. R. Morante1 and S. Mathur, Nanotechnology, 2007, 18, 424016. A. V. Marikutsa, M. N. Rumyantseva, L. V. Yashina and A. M. Gaskov, J Solid State Chem., 2010, 183, 2389. N. Barsan and U. Weimar, J. Phys.: Condens. Matter., 2003, 15, R813.

21) R. G. Pavelko, H. Daly, C. Hardacre, A. A. Vasilieva and E. Llobeta, Phys. Chem. Chem. Phys., 2010, 12, 2639.

22) A. Sharma, B. P. Singh, S. Dhar, A. Gondorf and M. Spasova, Surface Science, 2012, 606, L13.

23) C. Di Valentin, G. Pacchioni and A. Selloni, Phy. Rev. Lett., 2006, 97, 166803 .

24) V. Ligatchev, L. Yun Sim, Man-Fai Ng, X. Ning Xie and S. Wang Yang, J. Phys. D: Appl. Phys., 2008, 41, 245407.

25) V. Bonu, A. Das, MAPAN, 2013, 28, 259.

26) J. F. Scott, J. Chem. Phys., 1970, 53, 852.

27) F. Matossi, J. Chem. Phys., 1951, 19, 1543.

28) M. Ivanda, K. Furic, S. Music, M. Ristic, M. Gotic, D. Ristic, A. M. Tonejc, I. Djerdj, M. Mattarelli, M. Montagna, F. Rossi, M. Ferrari, A. Chiasera, Y. Jestin, G. C. Righini, W. Kiefer and R. R. Gon, calves, J. Raman Spectrosc., 2007, 38, 647.

29) L. Z. Liu, X. L. Wu, T. H. Li, S. J. Xiong, H. T. Chen and Paul K. Chu, Appl. Phy. Lett., 2011, 99, 251902.
E. J. H. Lee, C. Ribeiro, T. R. Giraldi, E. Longo, E. R. Leite and J. A. Varela, Appl. Phys. Lett., 2004, 84, 1745.

31) J. Button, C. G. Fonstad, and W. Dreybrodt, Phy. Rev. B. 1971, 4, 4539.

32) Jr H. He, Te H. Wu, C. L. Hsin, K. M. Li, L. J. Chen, Y. L. Chueh, L. J. Chou and Z. L. Wang, Small, 2006, 2, 116.

33) J. Hu, Y. Bando, Q. Liu and G. Golberg, Adv. Funct. Mater. 2003, 13,6 .

34) X. T. Zhou, F. Heigl, M. W. Murphy, T. K. Shama, T. Regier, I. Coulthard and R. I. R. Blyth, Appl. Phys. Lett., 2006, 89, 213109.

35) H. T. Chen, X. L. S. J. Wu Xiong, W. C. Zhang and J. Zhu, Appl Phys A, 2009, 97, 365.

36) S. Luo, J. Fan, W. Liu, M. Zhang, Z. Song, C. Lin, X. Wu and P. K Chu, Nanotechnology, 2006, 17, 1695.

37) C. Ke, W. Zhua, J. S. Pan and Z. Yang, Curr. Appl. Phy., 2011, 11, S306.

38) D. F. Cox, T. B. Fryberger, S. Semancik, Phy. Rev. B, 1988, 38, 2072.

39) Artem V. Marikutsa, M. N. Rumyantseva, L. V. Yashina and A. M. Gaskov, J. Solid State Chem. 2010, 183, 2389.

40) G. E. Walrafen J. Chem. Phy., 1975, 62, 297.

41) R. G. Pavelko, H. Daly, M. Hübner, C. Hardacre, and E. Llobet, J. Phys. Chem. C, 2013, 117, 4158.

42) Y. P. Varshni, Physica, 1967, 34, 149.

43) A. Schindler, R. Bindemann, K. Kreher, Phys. Status Solidi B, 1973, $\mathbf{5 9 ,} 439$. 


\section{Supplementary Information:}

TABLE SI. Size and Band gap of the $\mathrm{SnO}_{2}$ NPs with respect to annealing temperature.

\begin{tabular}{|c|c|c|c|}
\hline $\begin{array}{c}\text { Sample } \\
\text { (Annealing } \\
\text { Temperature })\end{array}$ & $\begin{array}{c}\text { Calculated size } \\
\text { Using LFRS } \\
(\mathrm{nm})\end{array}$ & $\begin{array}{c}\text { Measured size } \\
\text { using TEM } \\
(\mathrm{nm})\end{array}$ & $\begin{array}{c}\text { Band gap } \\
(\mathrm{eV})\end{array}$ \\
\hline $\begin{array}{c}\mathrm{A} \\
\left(100^{\circ} \mathrm{C}\right)\end{array}$ & $2.41 \pm 0.15$ & $2.4 \pm 0.1$ & $4.4 \pm 0.05$ \\
\hline $\begin{array}{c}\mathrm{B} \\
\left(200^{\circ} \mathrm{C}\right)\end{array}$ & $2.66 \pm 0.18$ & - & $4.25 \pm 0.05$ \\
\hline $\begin{array}{c}\mathrm{C} \\
\left(250^{\circ} \mathrm{C}\right)\end{array}$ & $3.1 \pm 0.22$ & - & $4.06 \pm 0.05$ \\
\hline $\begin{array}{c}\mathrm{D} \\
\left(300^{\circ} \mathrm{C}\right)\end{array}$ & $3.7 \pm 0.27$ & $4.1 \pm 0.2$ & $3.9 \pm 0.05$ \\
\hline $\begin{array}{c}\mathrm{E} \\
\left(500^{\circ} \mathrm{C}\right)\end{array}$ & - & $9.5 \pm 0.7$ & $3.67 \pm 0.05$ \\
\hline $\begin{array}{c}\mathrm{F} \\
\left(800^{\circ} \mathrm{C}\right)\end{array}$ & - & $25 \pm 1$ & 3.62 \\
\hline \multicolumn{2}{|c|}{} & & \\
\hline
\end{tabular}
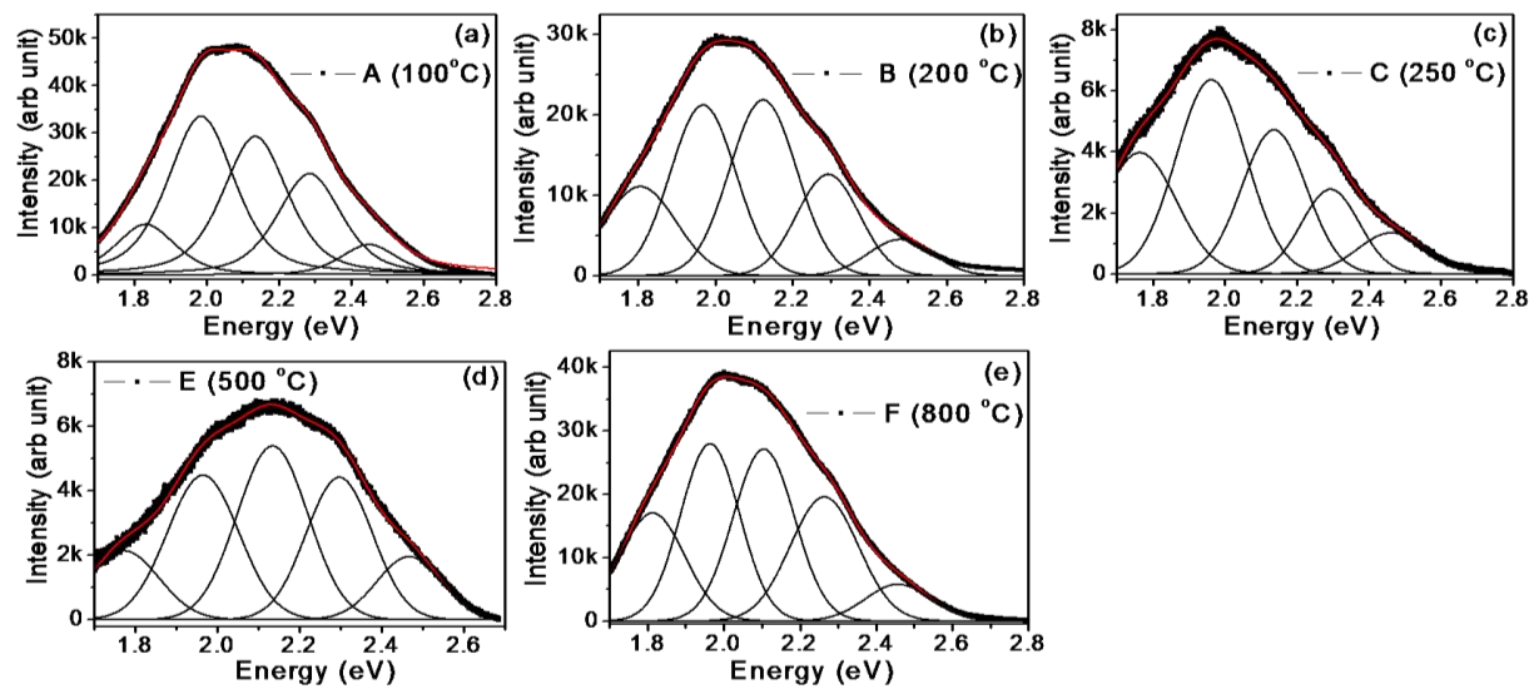

Fig. S1. Gaussian deconvolution of the PL spectra shown in Fig. 6. Area under each curve is deduced and shown in Table 1 


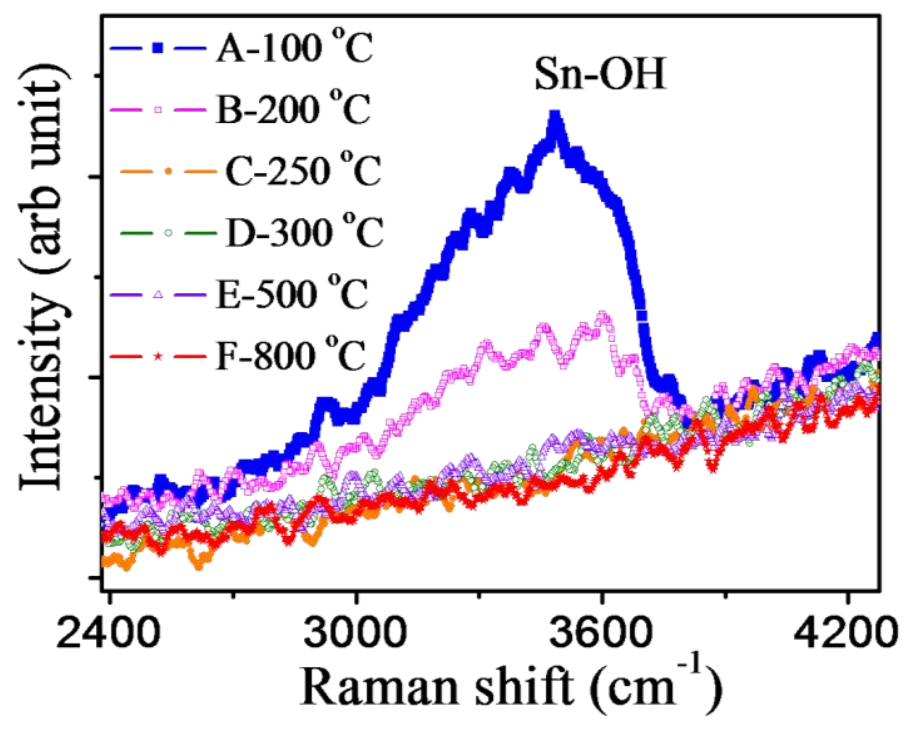

Fig. S2. Hydroxyl Raman mode of different size $\mathrm{SnO}_{2} \mathrm{NPs}$ with excitation $325 \mathrm{~nm}$. 